\title{
Eating Habits and Body Composition of International Elite Soccer Referees
}

\author{
by \\ Gabriele Mascherini ${ }^{1}$, Cristian Petri ${ }^{1}$, Elena Ermini ${ }^{1}$, Angelo Pizzi², \\ Antonio Ventura ${ }^{1}$, Giorgio Galanti ${ }^{1}$
}

Soccer referees are a specific group of the athletes' population whose careers peak from 30 to 45 years old. An athlete's performance is not only determined by physical training but also by a lifestyle, e.g. eating habits. The purpose of this study was to verify current eating habits and resulting body composition of a group of elite international soccer referees. At an international FIFA seminar 60 elite international soccer referees (aged $39.2 \pm 4.2$ years) were enrolled. A body composition assessment was performed with skinfold thickness and bio impedance analysis, while eating habits were evaluated with a multi-pass 24-hour dietary recall. The body composition showed a normal weight condition with a fat content of $11.4 \pm 2.5 \%$. Macronutrients showed a low level of carbohydrates (43.6 $\pm 5.4 \%)$ and a high level of fat $(40.0 \pm 4.5 \%)$. Micronutrients showed a low level of calcium, potassium, zinc, magnesium, iodine, vitamin B12 and vitamin B9. Even though their body composition was within the normal range, the current eating habits of elite international soccer referees did not appear to follow the nutrition guidelines. Therefore, it would be advisable to provide knowledge on nutrition for this particular category of sports subjects, an individualized nutritional plan would be advisable, in order to achieve and maintain better performance and appropriate body composition for their role.

Key words: match officials, soccer, fat mass, micronutrients, macronutrients.

\section{Introduction}

Soccer referees have the responsibility of applying the rules of the game and controlling players' behavior during matches. A referee's performance depends on numerous factors; the main ones are related to the ability to officiate a soccer match and to make decisions promptly, as well as the necessity to be close to the action (Wetson et al., 2012). There are other factors in the referee's performance that are related to their physical components; in particular, physical training, eating habits and body composition.

Soccer referees are a specific sample with particular characteristics; as their careers progress increasing physical activity is required alongside their increasing age: their career peak starts at the age of 30 and continues up to 45 years, when their athletic-cardiovascular performance can begin to decline (Reilly and Gregson, 2006).

The literature reports some studies about physical engagement in elite soccer referees: during a match they cover 10,000-13,000 $\mathrm{m}$ with a mean speed of around $6.5 \mathrm{~km} / \mathrm{h}$ and a mean heart rate of around $160-165$ beats $/ \mathrm{min}$, close to $85 \%$ of their maximum heart rate. Their oxygen uptake is close to $80 \%$ of its maximum and the estimated energy expenditure of referees during a game is from 4700 to $5600 \mathrm{~kJ}(1100-1350 \mathrm{kcal})$ (da Silva et al., 2008).

Physical demands and eating habits are closely interrelated and in recent years the literature and sport clubs have paid special attention to promoting nutritional strategies to

1 - Sports and Exercise Medicine Unit - Department of Experimental and Clinic Medicine - University of Florence, Italy.

2 - Italian Referee Association - Italian Soccer Federation - Italy. 
improve soccer players' performance (Petri et al., 2016). Currently, only a few data are available about the eating habits of soccer referees. In particular, Teixeira et al. (2014) observed that their carbohydrate intake was above the recommended amount and they found a deficiency in their micronutrient intake. Metz et al. (2015) observed a modification in the chronobiology and nature of their energy intake on match days, mainly to adapt their intake to the energy demands of the match. Martínez Reñón and Collado (2015) found that their diets did not contain sufficient calories from carbohydrates, in view of their occupation.

Body composition analysis is a method of assessing the balance between physical demands and eating habits; these two aspects are closely related to sports performance (Hawley et al., 2006).

In fact, for elite match officials the same nutritional strategies were recommended as for soccer players, discounting the differences in age, activity profile, body composition and physical engagement (Schenk et al., 2018).

The purpose of this study was to evaluate current nutritional habits and body composition in a large group of elite international match officials.

\section{Methods}

\section{Participants}

Sixty elite international soccer referees from six confederations were enrolled in a FIFA seminar held at the Italian Soccer Federal Technical Center of Coverciano (Italy) in March 2017. They were classified as elite because they were either registered with an athletic federation at the highest level or they were receiving financial support for their dedication to training and games. The referees trained five times a week and had one official match per week; each training session lasted around two hours.

The ethics committee of the Italian football association approved this study and all the participants signed their written informed consent prior to their inclusion in the study protocol.

\section{Measures}

The methodology used for the assessment of body composition was according to our previous study (Mascherini et al., 2015), integrating anthropometry, circumferences, skinfold thickness and whole body bioelectrical impedance analysis.

The anthropometric measurements were taken following "The International Society for the Advancement of Kinanthropometry" (ISAK) protocol (Marfell-Jones et al., 2012). All the anthropometric measurements were taken by the same researcher. His technical error was $5 \%$ and $1.5 \%$ for the skinfolds and all the other measurements, respectively. Body height $(\mathrm{cm})$ and mass $(\mathrm{kg})$ were measured using a medical scale (SECA $\left.{ }^{\circledR}\right)$ with a rod. The body mass index (BMI) was calculated using the body formula mass $/$ height ${ }^{2}\left(\mathrm{~kg} / \mathrm{m}^{2}\right)$. The bicep girth, waist girth and hip girth $(\mathrm{cm})$ were measured with a narrow, metallic and inextensible measuring tape $\left(\right.$ Lufkin ${ }^{\circledR}$ model $\mathrm{W} 606 \mathrm{PM}$; precision $\left.=1 \mathrm{~mm}\right)$. The skinfolds were measured with a skinfold caliper (Holtain Ltd, Crymmych, UK; precision $=0.2 \mathrm{~mm}$ ) at nine anatomical sites around the body (triceps, subscapular, biceps, iliac crest, suprailiac, pectoral, abdominal, thigh, calf). The mean of three equations was then used to convert the skinfold values to a Fat Mass percentage (Mascherini et al., 2015). An additional variable was the Fat Mass Index (FMI $=\mathrm{FM} / \mathrm{h}^{2}$ expressed in $\mathrm{kg} / \mathrm{m}^{2}$ ) in order to differentiate between gender heights. The Fat Free Mass (FFM) was calculated as body weight - Fat Mass (Akcland et al., 2012).

Whole-body impedance was generated in soft tissues when a current flow passed through the body and was measured using skin electrodes that were placed on the hands and feet (BIA 101 Sport Edition, Akern, Florence, Italy). Resistance $(R Z, \Omega)$ was the opposition to the flow of an alternating current, at any current frequency, through intra and extracellular ionic solutions and reflected the amount of body water, while Reactance $(\mathrm{XC}, \Omega$ ) was the dielectric or capacitive component of cell membranes and organelles, and tissue interfaces. Starting from these variables, the estimate of the following body compartments was derived: body cellular mass (BCM in $\mathrm{kg}$ ), extracellular mass (ECM in $\mathrm{kg}$ ), total body water (TBW in L), extracellular water (ECW, \% TBW), intracellular water (ICW, \% TBW). Additional variables included BCMI in $\mathrm{kg} / \mathrm{h}^{2}, \mathrm{ECMI}$ in $\mathrm{kg} / \mathrm{h}^{2}$ and TBWI in L/h (Mascherini et al., 2015).

Soccer referees were asked to complete a multi-pass 24-hour dietary recall (Deakin et al., 2015). They were asked to indicate all the foods 
they had consumed. In order to facilitate the completion of the recall and to improve its accuracy, a food diary was provided for each participant. They were educated about the protocols for documenting intake and a researcher assisted soccer referees with the accuracy of their self-reported information. The energy intake and food choices were qualitatively and quantitatively assessed using the Progetto Dieta software (Progetto Dieta 2.0.22213 Beta software, Italy). Specifically, we assessed macronutrients, carbohydrates (CHO), protein (PRO) and fats (FAT) in \% and $\mathrm{g} / \mathrm{kg}$ of body mass; these variables were analyzed following the international guidelines of the American College of Sports Medicine (Thomas et al., 2016). We also assessed and analyzed micronutrients, minerals and vitamins following the European Food Safety Authority (EFSA, 2006) and the Italian Institute for Food Research and Nutrition (INRAN) guidelines (Turrini, 1996).

\section{Design and Procedures}

The present study was observational research. The study participants were subjected to body composition assessments in the early morning with no breakfast, no physical activity in the previous $12 \mathrm{~h}$ and no long trips on the previous day. Then the nutritional habits of each referee enrolled in the study were analyzed.

Statistical Analysis

Since this was an observational study, no comparisons were made between data. Data are expressed as mean $\pm \mathrm{SD}$. The results shown in the present study were used for comparison with American College of Sports Medicine nutritional guidelines (Thomas et al., 2016) and some discrepancies were found.

The data were analyzed using the statistical package IBM SPSS Statistics for Windows (SPSS Inc., Chicago, IL, USA).

\section{Results}

The body composition results are reported in Table 1. These data describe a normal weight group $\left(\mathrm{BMI}=23.3 \pm 1.5 \mathrm{~kg} / \mathrm{m}^{2}\right)$ with a fat mass of $11.4 \pm 2.5 \%$ and an FMI of $4.9 \pm 1.3 \mathrm{~kg} / \mathrm{m} 2$ measured using plicometry. The bioimpedance analysis showed that the total body water was at the upper limits of the normal range $(25.5 \pm 2.3$ $\mathrm{L} / \mathrm{m})$, mainly with an intracellular distribution (ICW $=60.8 \pm 2.6 \%$ ). In addition, a body cell mass within the normal range $(\mathrm{BCM}=39.2 \pm 4.7 \mathrm{~kg})$ and fat mass equal to $17.1 \pm 1.8 \%$ were found.

Dietary habits in terms of $\mathrm{CHO}, \mathrm{PRO}$, FAT and alcohol $(\%$ and $\mathrm{g} / \mathrm{kg})$ are reported in Table 2. These data show lower $\mathrm{CHO}$ intake (43.6 $\pm 5.4 \%$ and $3.1 \pm 0.8 \mathrm{~g} / \mathrm{kg}$ ) and greater FAT intake $(40.0 \pm 4.5 \%$ and $1.3 \pm 0.3 \mathrm{~g} / \mathrm{kg})$ compared to international guidelines. The PRO intake appeared to be within the lower limits $(1.1 \pm 0.3$ $\mathrm{g} / \mathrm{kg})$.

Micronutrients in terms of vitamins and minerals are reported in Table 3. Out of the eight minerals analyzed, five were below the guidelines (calcium $661.8 \pm 189.2 \mathrm{mg} /$ day, potassium $2929.3 \pm$ $794.3 \mathrm{mg} /$ day, zinc $10.3 \pm 2.5 \mathrm{mg} /$ day, magnesium $295.6 \pm 82.6 \mathrm{mg} /$ day, iodine $21.2 \pm 9.4 \mu \mathrm{g} /$ day) Vitamin B12 $(0.3 \pm 0.2 \mu \mathrm{g} /$ day $)$ and vitamin B9 $(381.0 \pm 119.6)$ showed values below the recommendations (European Food Safety Authority, 2006).

\section{Discussion}

Appropriate energy intake is essential for optimal performance. Determining intake in terms of macronutrients and micronutrients is the main way to carry out an assessment as accurately as possible. The present study shows some critical aspects in the eating habits of elite international soccer referees and their consequent body composition variables need to improve for this sample to be considered elite athletes.

Referees should, however, be considered athletes; elite soccer referees in fact have values of $51.9 \mathrm{ml} \cdot \mathrm{kg} \cdot \mathrm{min}$ of maximum oxygen uptake (Castagna et al., 2018). Soccer players cover the same total distance as referees during matches: referees cover about 10.000-13.000 $\mathrm{m}$ with a mean speed of around $6.5 \mathrm{~km} / \mathrm{h}$ (Clemente et al., 2013). Their average work rate during matches at a heart rate of around $160-165$ beats/min $(85 \%$ of their maximum heart rate) is close to $70-80 \%$ of their maximum oxygen uptake, corresponding to an energy expenditure of approximately $5700 \mathrm{~kJ}$ (1360 kcal) (Bangsbo et al., 2006).

From elite soccer referees high levels of performance are expected, therefore physical training is constantly monitored and updated individually, yet this attention does not concern their nutrition. 
Table 1

Anthropometrics, skinfold thickness and bio impedance variables of the referee group. Data are expressed as mean and S.D.

\begin{tabular}{|c|c|c|c|c|}
\hline & & Mean \pm S.D. & Minimum & Maximum \\
\hline \multirow{4}{*}{ Anthropometry } & Age (years) & $39.2 \pm 4.2$ & 29.5 & 50.0 \\
\hline & Height (m) & $1.818 \pm 0.58$ & 1.710 & 1.940 \\
\hline & Weight (kg) & $77.1 \pm 6.8$ & 61.0 & 94.0 \\
\hline & BMI $\left(\mathrm{kg} / \mathrm{m}^{2}\right)$ & $23.3 \pm 1.5$ & 20.6 & 25.8 \\
\hline \multirow{4}{*}{ Circumferences } & Waist (cm) & $77.8 \pm 4.7$ & 69.0 & 88.0 \\
\hline & Hip (cm) & $96.0 \pm 3.7$ & 88.0 & 103.0 \\
\hline & Biceps (cm) & $28.4 \pm 2.2$ & 24.8 & 34.5 \\
\hline & $\sum 9 \mathrm{sk}(\mathrm{mm})$ & $76.2 \pm 20.6$ & 46.5 & 130.8 \\
\hline \multirow{5}{*}{$\begin{array}{l}\text { Skinfold } \\
\text { thickness }\end{array}$} & $\sum 7 \mathrm{sk}(\mathrm{mm})$ & $63.7 \pm 17.3$ & 38.9 & 116.8 \\
\hline & FM $(\%)$ & $11.4 \pm 2.5$ & 7.8 & 17.0 \\
\hline & FM (kg) & $8.9 \pm 2.3$ & 5.8 & 12.9 \\
\hline & FMI $\left(\mathrm{kg} / \mathrm{m}^{2}\right)$ & $4.9 \pm 1.3$ & 2.7 & 6.5 \\
\hline & FFM (Kg) & $68.3 \pm 5.8$ & 53.4 & 84.3 \\
\hline \multirow{12}{*}{ Bio impedance } & $\mathrm{RZ}(\Omega)$ & $494.1 \pm 62.3$ & 380 & 622.0 \\
\hline & XC $(\Omega)$ & $66.8 \pm 8.2$ & 50.0 & 84.0 \\
\hline & $\mathrm{PA}\left({ }^{\circ}\right)$ & $7.7 \pm 0.7$ & 5.9 & 9.2 \\
\hline & BCM (kg) & $39.2 \pm 4.7$ & 29.1 & 51.2 \\
\hline & BCMI $\left(\mathrm{kg} / \mathrm{m}^{2}\right)$ & $11.9 \pm 1.3$ & 9.3 & 14.7 \\
\hline & $\mathrm{ECM}(\mathrm{kg})$ & $24.7 \pm 2.7$ & 20.5 & 32.0 \\
\hline & ECMI $\left(\mathrm{kg} / \mathrm{m}^{2}\right)$ & $7.5 \pm 0.6$ & 6.2 & 8.8 \\
\hline & TBW (L) & $46.5 \pm 4.8$ & 36.6 & 61.2 \\
\hline & TBWI (L/m) & $25.5 \pm 2.3$ & 21.0 & 31.9 \\
\hline & ICW (\%) & $60.8 \pm 2.6$ & 53.3 & 65.6 \\
\hline & ECW (\%) & $39.2 \pm 2.6$ & 34.4 & 46.7 \\
\hline & FM (\%) & $17.1 \pm 1.8$ & 13.5 & 20.6 \\
\hline
\end{tabular}

Legend: $B M I=$ Body Mass Index, $\sum 9$ sk = sum of 9 skinfold, $\sum 7$ sk $=$ sum of 7 skinfold, $F M=$ Fat Mass, FMI = Fat Mass Index; FFM = Fat Free Mass; $R Z=$ Resistance, $X C=$ Reactance, $P A=$ Phase Angle $B C M=$ Body Cell Mass, BCMI = Body Cell Mass Index,

$E C M=$ Extra Cell Mass, ECMI = Extra Cell Mass Index, TBW = Total Body Water, $T B W I=$ Total Body Water Index, ICW = Intra Cellular Water, ECW = Extra Cellular Water, $F M=$ Fat Mass 
Table 2

Macronutrients intake of the referees' group. Data are expressed as mean and S.D for comparison with American College of Sports Medicine guidelines (Thomas et al., 2016).

\begin{tabular}{ccccc}
\hline & \% intake & Guidelines & $\mathrm{g} / \mathrm{kg}$ intake & \\
& & & & Guidelines \\
\hline Carbohydrates & $43.6 \pm 5.4$ & $55.0-70$ & $3.1 \pm 0.8$ & $5.0-7.0$ \\
Protein & $16.4 \pm 2.2$ & $15.0-20$ & $1.1 \pm 0.3$ & $1.2-2.0$ \\
Fat & $40.0 \pm 4.5$ & $<30$ & $1.3 \pm 0.3$ & 1.0 \\
Alcohol & $2.5 \pm 3.2$ & 0 & $0.1 \pm 0.1$ & 0 \\
\hline
\end{tabular}

Table 3

Micronutrient intake of the referees group. Data are expressed as mean and S.D. for comparison with the European Food Safety Authority (European Food Safety Authority, 2006) and Italian Institute for Food Research and Nutrition (INRAN) guidelines (Turrini, 1996).

\begin{tabular}{|c|c|c|c|}
\hline & & Intake & Guidelines \\
\hline \multirow{7}{*}{ Minerals } & Calcium* (mg/day) & $661.8 \pm 189.2$ & 900 \\
\hline & Sodium (mg/day) & $1164.4 \pm 272.2$ & 575 \\
\hline & Potassium* (mg/day) & $2929.3 \pm 794.3$ & 3000 \\
\hline & Phosphorus (mg/day) & $1422.8 \pm 333.5$ & 1000 \\
\hline & Iron (mg/day) & $17.3 \pm 4.5$ & 13 \\
\hline & Zinc $^{*}$ (mg/day) & $10.3 \pm 2.5$ & 11 \\
\hline & Magnesium* (mg/day) & $295.6 \pm 82.6$ & 420 \\
\hline \multirow{10}{*}{ Vitamins } & Iodine $^{*}(\mu \mathrm{g} /$ day $)$ & $21.2 \pm 9.4$ & 100 \\
\hline & A ( $\mu \mathrm{g} /$ day $)$ & $1282 \pm 489.0$ & 700 \\
\hline & $\mathrm{B}_{1}$ (mg/day) & $1.6 \pm 0.4$ & 1.1 \\
\hline & $\mathrm{B}_{2}$ (mg/day) & $1.9 \pm 0.5$ & 1.3 \\
\hline & $\mathrm{B}_{6}$ (mg/day) & $2.3 \pm 0.7$ & 2.0 \\
\hline & $\mathrm{B}_{9}^{*}(\mu \mathrm{g} /$ day $)$ & $381.0 \pm 119.6$ & 400 \\
\hline & $\mathrm{B}_{12^{*}}(\mu \mathrm{g} /$ day $)$ & $0.3 \pm 0.2$ & 1.0 \\
\hline & $\mathrm{C}$ & $137.1 \pm 70.5$ & 113 \\
\hline & $\mathrm{D}$ & $6.8 \pm 3.0$ & 3.0 \\
\hline & E & $17.2 \pm 2.8$ & 11 \\
\hline
\end{tabular}

* = data lower in comparison to international guidelines. 
Elite athletes receive recommendations with regard to their nutritional strategies, which should therefore also be directed toward referees, who are on the average 15 years older than soccer players. The literature provides guidelines for proper nutrition in athletes (Thomas et al., 2016), but currently soccer referees do not seem to follow them.

Despite international soccer referees having body composition variables within the normal range, their current eating habits show low levels of $\mathrm{CHO}$ and high levels of FAT. Adequate carbohydrate intake is important for optimal physical performance: $\mathrm{CHO}$ provide a key substrate for the brain and central nervous system and is a versatile substrate for muscular work, where it can support exercise over a large range of intensities due to its utilization by both anaerobic and oxidative pathways (Spriet, 2014). The athletic engagement of soccer referees mainly features prolonged, sustained or intermittent high-intensity exercise; therefore, there is significant evidence that this kind of effort is enhanced by strategies that maintain high carbohydrate availability, while the depletion of these stores is associated with fatigue in the form of reduced work rates, impaired skill and concentration as well as an increased perception of effort (Cole et al., 2014).

Dietary protein interacts with exercise, providing both a trigger and a substrate for the synthesis of contractile and metabolic proteins as well as enhancing structural changes in tendons and bones. Current data suggest that the dietary protein intake necessary to support metabolic adaptation, repair, remodeling and for protein turnover generally ranges from 1.2 to 2.0 $\mathrm{g} / \mathrm{kg} /$ day. Lower intake is not indicated to prevent fat-free mass loss (Phillips and Van Loon, 2011).

Chronic adaptation to high-fat lowcarbohydrate diets appears to reduce the availability of $\mathrm{CHO}$ as an exercise substrate. Therefore, subjects on this diet sacrifice their ability to make high-intensity efforts during matches (Burke, 2015).

Alcohol consumption may be part of a well-chosen diet and social life, but acute or chronic use can have negative effects on physical performance, decision making and body composition due to its effects on the acid-base balance, glucose metabolism and cardiovascular function (Barnes, 2014).

The intake of some micronutrients is below the recommendations (European Food Safety Authority, 2006): magnesium is involved in numerous processes that affect muscular function including oxygen uptake, energy production and electrolyte balance. There is evidence that marginal magnesium deficiency impairs exercise performance and amplifies the negative consequences of strenuous exercise (e.g. oxidative stress). Calcium is important for the regulation of muscle contraction and nerve conduction; low levels of this micronutrient are associated with low bone-mineral density and stress fractures (Lukaski, 2004). At present, the only physiological role known for iodine in the human body is in the synthesis of thyroid hormones by the thyroid gland. The physiological role of thyroid hormones is to control several metabolic processes in the body: carbohydrate, fat, protein, vitamin, and mineral metabolism (Stanbury, 1960). Zinc is an essential component of enzymes participating in the metabolism of carbohydrates, lipids, proteins and other micronutrients (Lukaski et al., 1984). A decrease in iodine and zinc will affect energy production, lipolysis, neoglucogenesis and glycolysis, all of which can compromise an athlete's performance.

With respect to vitamins, a decrease in vitamin B9, folate, reduces cell division, for example, red blood cells, thereby producing anemia; it also affects cells derived from bone marrow, leading to leucopenia and thrombocytopenia, and cells in the lining of the gastrointestinal tract, inducing malabsorption. Low levels of vitamin B12, cobalamin, are also found in individuals who consume diets completely free of animal products. Cobalamin is strictly related to folate in the methylation cycle for the myelination of the peripheral nerves; therefore, its reduction results in less nervous function. Insufficient vitamin intake can have negative implications for supporting athletic performance (Volpe, 2007).

Body composition applications in sport optimize performance, especially when excessive body fat can affect the result: this is an aspect of considerable interest to scientists, athletes and coaches. Male soccer players in particular show a fat mass percentage of their body mass of around 10\% (Petri et al., 2016), although for referees only 
few studies are available in the literature and recent data report a range between 11.7-13.7\% obtained from skinfold thickness (Casajús and Gonzalez-Aguero, 2015; Petri et al., 2017). Our results, which were obtained using the same methodology, show slightly lower average values, but they are still in line with the previously reported data.

Recently published research on the body composition of 52 referees during the 2012 FIFA World Cup was similar compared with the present study for anthropometry, but showed a higher fat mass $(20.4 \pm 3.6 \%$ vs. $17.1 \pm 1.8 \%)$ and a lower cell mass $(33.8 \pm 3.5 \mathrm{~kg}$ vs. $39.2 \pm 4.7 \mathrm{~kg})$ evaluated using the same BIA 101 device (Schenk et al., 2018). Therefore, it can be assumed that some initial nutritional care has been adopted in recent years.

This is the first study involving a large group of international match officials in order to assess their nutritional intake and body composition. In addition to previous studies carried out on this specific group, the assessment of eating habits in this study analyzed both the macro and micronutrients. With regard to body composition, an assessment of both fat mass (with skinfolds) and fat-free mass (with bioimpedance) was performed.

The sample's heterogeneity allowed for a broad generalization of the results. However, the micronutrient analysis was not easy to perform because there are no single international recommendations for vitamin and mineral intake: in fact, different ethnicities have different reference values (European Food Safety Authority, 2006).

According to the group's specific characteristics, basic nutritional guidelines and recommendations are defined. Adequate implementation requires a general education in sports nutrition and professional mentoring about adapting to individual characteristics and special needs (Schenk et al., 2018).

At present, the authors cannot demonstrate that any modifications to the current nutrition table of referees will allow them to achieve better performance, therefore a future direction of study may be to correct the current eating habits of the elite soccer referees, verifying the effects on the variables present in the literature related to the physical engagement and body composition.

\section{Practical implications}

Elite soccer referees did not follow the nutritional guidelines for athletes; therefore, a nutrition plan should be advisable for these subjects. This plan should be individualized, also considering ethnicity. The national associations that follow soccer referees should have experts in sports nutrition in their staff.

\section{Conclusion}

The current eating habits in terms of macronutrients and micronutrients of international soccer referees do not appear to follow athletes' guidelines. However, this population has specific characteristics that differ from those of the competitive athlete. It is therefore necessary to pay more attention to the category of referees in order to accurately indicate the various nutritional recommendations, while respecting the habits of different ethnicities, to be followed in order to achieve optimal performance and maintain an appropriate body composition for their role.

\section{References}

Ackland TR, Lohman TG, Sundgot-Borgen J, Maughan RJ, Meyer NL, Stewart AD, Müller W. Current status of body composition assessment in sport: review and position statement on behalf of the ad hoc research working group on body composition health and performance, under the auspices of the I.O.C. Medical Commission. Sports Med, 2012; 42(3): 227-249

Bangsbo J, Mohr M, Krustrup P. Physical and metabolic demands of training and match-play in the elite football player. J Sports Sci, 2006; 24(7): 665-74

Barnes MJ. Alcohol: impact on sports performance and recovery in male athletes. Sports Med, 2014; 44(7): 909-919

Burke LM. Re-examining high-fat diets for sports performance: did we call the "nail in the coffin" too soon? Sports Med, 2015; 45(1): 33-49 
Casajús JA, Gonzalez-Aguero A. Body composition evolution in elite football referees; an eleven-years retrospective study. Int J Sports Med, 2015; 36(7): 550-3. doi: 10.1055/s-0034-1398582

Castagna C, Bizzini M, D’Ottavio S, Araújo Póvoas SC. Sex Differences in Aerobic Fitness in Top-Class Soccer Referees. J Strength Cond Res, 2018; 32(11): 3216-3221. doi: 10.1519/JSC.00000000000002292

Clemente FM, Couceiro MS, Martins FM, Ivanova MO, Mendes R. Activity profiles of soccer players during the 2010 world cup. J Hum Kinet, 2013; 38: 201-11. doi: 10.2478/hukin-2013-0060

Cole M, Coleman D, Hopker J, Wiles J. Improved gross efficiency during long duration submaximal cycling following a short-term high carbohydrate diet. Int J Sports Med, 2014; 35(3): 265-269

Deakin V, Kerr D, Boushey C. Measuring nutritional status of athletes: clinical and research perspectives. In: Burke L, Deakin V, eds. Clinical Sports Nutrition. 5th eds. North Ryde, Australia: McGraw-Hill; 27-53; 2015

da Silva AI, Fernandes LC, Fernandez R. Energy expenditure and intensity of physical activity in soccer referees during match-play. J Sports Sci Med, 2008; 7(3): 327-34

European Food Safety Authority, Scientific Panel on Dietetic Products, Nutrition and Allergies, Scientific Committee on Food. (2006). Tolerable upper intake levels for vitamins and minerals, Available at: http://www.efsa.europa.eu/sites/default/files/efsa_rep/blobserver_assets/ndatolerableuil.pdf accessed on 29.01.2019

Hawley JA, Tipton KD, Millard-Stafford ML. Promoting training adaptations through nutritional interventions. J Sports Sci, 2006; 24(7): 709-21

Lukaski HC. Vitamin and mineral status: Effects on physical performance. Nutrition, 2004; 20(7-8): 632-644

Lukaski HC, Bolonchuk WW, Klevay LM, Milne DB, Sandstead HH. Changes in plasma zinc content after exercise in men fed a low-zinc diet. Am J Physiol, 1984; 247: E88-E93

Marfell-Jones MJ, Stewart AD, de Ridder JH. International standards for anthropometric assessment. Wellington. New Zealand: International Society for the Advancement of Kinanthropometry; 2012

Martínez Reñón C, Collado PS. An assessment of the nutritional intake of soccer referees. J Int Soc Sports Nutr, 2015; 12: 8. doi: 10.1186/s12970-015-0068-9

Mascherini G, Gatterer H, Lukaski H, Burtscher M, Galanti G. Changes in hydration. body-cell mass and endurance performance of professional soccer players through a competitive season. J Sports Med Phys Fitness, 2015; 55(7-8): 749-55

Mascherini G, Petri C, Galanti G. Integrated total body composition and localized fat-free mass assessment. Sport Sci Health, 2015; 11(2): 217-225. doi:10.1007/s11332-015-0228-y

Metz L, Deleuze T, Pereira B, Thivel D. Nutritional Adaptations in Elite Soccer Referees: First Evidence and Perspectives. J Hum Kinet, 2015; 27; 46: 77-83

Petri C, Mascherini G, Castagna C, Pizzi A, Collina P, Galanti G. Body composition of italian soccer referees Med Sci Sports Exerc, 2017; 49 (Suppl 5): P393, doi: 10.1249/01.mss.0000517955.47723

Petri C, Mascherini G, Pengue L, Galanti G. Dietary habits in elite soccer players. Sport Sci Health, 2016; 12(1), 113-119 doi.org/10.1007/s11332-016-0264-2

Phillips SM, Van Loon LJ. Dietary protein for athletes: from requirements to optimum adaptation. J Sports Sci, 2011; 29 (Suppl 1): S29-38

Reilly T, Gregson W. Special populations: the referee and assistant referee. J Sports Sci, 2006; 24(7): 795-801

Schenk K, Bizzini M, Gatterer H. Exercise physiology and nutritional perspectives of elite soccer refereeing. Scand J Med Sci Sports, 2018; 28(3): 782-793. doi: 10.1111/sms.12989

Spriet LL. New insights into the interaction of carbohydrate and fat metabolism during exercise. Sports Med, 2014; 44(Suppl 1): S87-96

Stanbury JB. Physiology of endemic goitre. In: Endemic goitre. Geneva, World Health Organization, 261-262; 1960

Teixeira VH, Gonçalves L, Meneses T, Moreira P. Nutritional intake of elite football referees. J Sports Sci, 2014; 32(13): 1279-85. doi: 10.1080/02640414.2014.887851

Thomas DT, Erdman KA, Burke LM. American College of Sports Medicine Joint Position Statement. Nutrition and Athletic Performance. Med Sci Sports Exerc, 2016; 48(3): 543-68. doi: 10.1249/MSS.0000000000000852 
Turrini A. Vitamin and mineral intake in Italy. National survey 1994-1996, INRAN Rome. 1996

Volpe SL. Micronutrient requirements for athletes. Clin Sports Med, 2007; 26(1): 119-30

Weston M, Castagna C, Impellizzeri FM, Bizzini M, Williams AM, Gregson W. Science and medicine applied to soccer refereeing: an update. Sports Med, 2012; 42(7): 615-31. doi: 10.2165/11632360-000000000-00000

\section{Corresponding author:}

\section{Gabriele Mascherini,}

Largo Brambilla 3, 50100 Florence. Italy

orcid.org/0000-0002-8842-0354

phone +393396895925

E-mail: gabriele.mascherini@unifi.it 